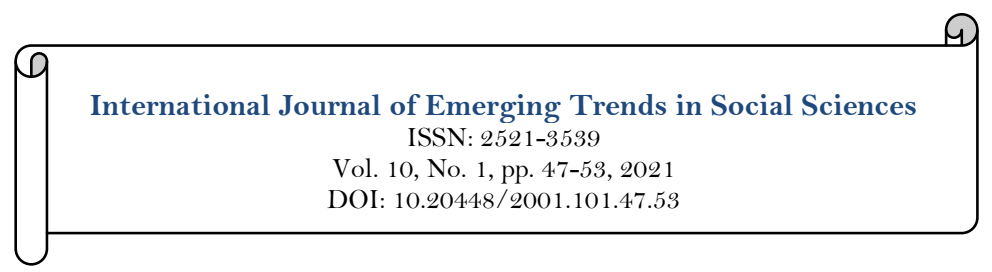

\title{
A Study on the Correlation between China's Stock Market and Economic Growth
}

\author{
Xin KAI' \\ Jiexin LIAO ${ }^{2}$ \\ 'Ph.D Candidate, School of Economics, Central University of Finance and Economics, Changping District, Beijing, China. \\ Email:kaixin@email.cufe.edu.cn \\ ${ }^{2}$ Postgraduate, School of Finance, Central University of Finance and Economics, Changping District, Beijing, China.
}

\begin{abstract}
Stock is an important financial tool, however, due to the imperfect development of China's stock market, the role of the stock market as an economic barometer is not clear. Meanwhile, there is no consistent conclusion about the correlation between them in the literature. Therefore, based on theoretical models and through empirical methods including regression analysis, Granger causality test, VAR model, this paper tests the relationship between China's stock market and economic growth from the perspectives of correlation, causality and dynamic relationship, by which we try to make the research more comprehensive and convincing. The results show that these methods are highly consistent: the scale of China's stock market is large, which makes a great contribution to and has a strong relationship with the economic growth, but the relationship between the liquidity and volatility of the stock market and economic growth is weak. Based on the findings, the products, structure and rules of China's stock market need to be improved in the future.
\end{abstract}

$$
\text { structure and rules of China's stock market need to be improved in the future. }
$$

Keywords:
Stock market
Economic growth
Correlation
VAR model.
Licensed:
This work is licensed under a
Creative Commons Attribution 4.0
License.
Publisher:
Scientific Publishing Institute
Received: 10 February 2021
Revised: 15 March 2021
Accepted: 26 April 2021
Published: 24 May 2021
( Corresponding Author)

Funding: This study received no specific financial support.

Competing Interests: The authors declare that they have no competing interests.

\section{Introduction}

The stock market is an important part of financial markets. The stock market plays an important role in raising funds, dispersing risks, optimizing the allocation of resources, promoting technological progress, and improving enterprise governance. Therefore, the stock market is often called the barometer of the economy. As the world's second largest economy, China's stock market has also played a role in promoting China's economic development since the establishment of the Shanghai Stock Exchange in 1990. By the end of 2020, the total market value of stocks accounts for about $80 \%$ of GDP. However, due to the immature development of China's stock market, it often rises rapidly and then brings a long bear market, such as the stock market disaster in 2007 and 2015, which brought about a terrible impact on economic growth.

Due to the unclear effect of the stock market on economic growth, it's important to study the real relationship between them, such as the size of the stock market, volatility and other effects on economic growth, so as to contribute to the formulation of sustainable development policies. Based on relevant literature and theory, this paper will empirically analyze the correlation between China's stock market and economic growth. The following parts are as follows: the second part is the literature review, the third part is the mechanism analysis of the stock market in promoting economic growth, the fourth part is the empirical research, and the fifth part is the conclusion. 


\section{Literature Review \\ 2.1. Theoretical Study on Stock Market and Economic Growth}

McKinnon and Shaw started relevant research in the 1970s. They studied the impact of financial liberalization on economic growth, namely the financial deepening theory, which is one of the most influential researches. Cho (1986) introduced credit rationing theory and stock market on the basis of financial deepening theory, and pointed out that banks could not allocate capital effectively because of incomplete information in the market, but the stock market could avoid moral hazard and adverse selection, so as to obtain the maximum expected return. Therefore, the full development of the stock market is a necessary condition for complete financial liberalization and economic growth. Chen, Wang, and Chen (2004) points out that the stock market has a great advantage in financing, especially for high-tech and innovative enterprises, due to its specific characteristics of pricing, investment diversification and risk diversification. Yang and Kuang (2004) also have a similar view. Their research uses the Pagano endogenous growth model to show that the stock market can reduce leakage, promote innovation and increase liquidity to promote economic growth.

\subsection{Empirical Study on Stock Market and Economic Growth}

Levine and Zervos (1998) studied the correlation between stock market development and economic growth in many countries. The research shows that stock market and financial intermediaries are positively correlated and complementary. Stock market development and economic growth also have a significant positive correlation in the long run, and stock market is gradually replacing loan market as one of the most important channels to promote economic growth. Arestis, Demetriades, and Luintel (2001) conducted an empirical study on the stock market and economic growth of five developed countries, such as the United Kingdom and the United States, through the method of time series. The results show that the stock market is only a small part of the financial market, and only has a certain contribution to economic development in the long run. Moreover, compared with the capital market, the financial system based on banks has a stronger driving effect on economic growth. The study also believes that some cross-border panel studies exaggerate the role of stock market in promoting economic growth. Mao and $\mathrm{Wu}$ (2007) empirically tested the correlation between stock market and economic growth in Australia and other developed countries through VEC, VAR models. The study found that the correlation between stock market and economic growth was higher in the period of economic upturn, but not significant in the period of economic downturn or weakness. Brown, Martinsson, and Petersen (2017) analyzed the stock market, credit market and technology oriented economic growth of 38 countries by variance regression method. The research shows that there is a significant positive correlation between the stock market and the size of technology sector. Therefore, the development and improvement of the stock market will help to establish more technology intensive and innovation oriented industries and companies, thus, it is more conducive to long-term economic growth and structural improvement.

\subsection{Study on China's Stock Market and Economic Growth}

Tan (1999) shows that traditional banks are more effective in credit allocation than stock market, and stock market and economic growth even show negative correlation in China. Wang and Ma (2005); Song and Li (2014)and other studies have similar views. These scholars believe that the low significance of the two may be related to the imperfect of China's stock market, incomplete market structure, intervention and other factors. Liu (2011) studied the correlation between the two from the perspective of stock market liquidity. He believed that turnover had a positive effect on economic growth, while turnover rate was negative, indicating that excessive turnover rate caused excessive volatility, which was not conducive to economic growth. Duan and Yang (2009) showed that the trading rate and capitalization rate of the stock market have a significant role in promoting economic growth through VAR model.

According to the literature, There is no consistent conclusion about the correlation between stock market and economic growth. This paper argues that the application of different empirical methods to study the correlation between the stock market and economic growth is an important reason for the inconsistency of conclusions. Different methods focuses on different perspectives, thus the conclusions are not complete. Therefore, this paper will first theoretically analyze the mechanism of the stock market promoting economic growth, and then comprehensively test the correlation between China's stock market and economic growth through regression analysis, Granger causality test and VAR model, namely from the perspectives of correlation, causality and dynamic relationship so as to make the conclusion more complete and convincing.

\section{Analysis on the Mechanism of Stock Market Promoting Economic Growth}

Among the relevant models of stock market promoting economic growth, the growth model based on AK model is a representative one:

$$
Y_{t}=A K_{t}
$$

In Equation 1, $Y_{t}$ and $K_{t}$ represents the total output and total capital of period t respectively, and $A$ is the capital output rate or technical coefficient. The model has three hypotheses: first, it assumes that this is a closed economy with only two sectors and the total population remains unchanged; The second is to assume 
that the manufacturer only produces one product, which can be used for both consumption and investment, and the depreciation rate of investment is $\delta$; Third, technological progress is exogenous and remains unchanged. Therefore, the total investment $I_{t}$ of phase $\mathrm{t}$ can be expressed as:

$$
I_{t}=K_{t+1}-(1-\delta) K_{t}
$$

In a closed economy with two sectors, total saving is equal to total investment. However, due to the operating costs of financial intermediaries, such as handling charges, manager's commission, it is assumed that in the process of financing, the rate of saving leakage is $(1-\varphi)$. Then we can get the following results:

$\begin{aligned} \varphi S_{t} & =I_{t} \\ \text { The economic growth rate of } t+1 \text { period: } g_{t+1} & =\frac{Y_{t+1}-Y_{t}}{Y_{t}}=Y_{t+1} / Y_{t}-1\end{aligned}$

Substituting Equation 1 into Equation4 we can get: $g_{t+1}=\frac{A K_{t+1}}{A K_{t}}-1=K_{t+1} / K_{t}-1(5)$

Substituting Equation 3 into Equation 2, we can get: $t \varphi S_{t}=K_{t+1}-(1-\delta) K_{t}$

Divide both sides of Equation 6 by $K_{t}$ and substitute it into Equation 5, we can get:

$$
\frac{\varphi S_{t}}{K_{t}}=g_{t+1}+\delta
$$

Finally, we substitute Equation 1 into Equation 7 and assume that the proportion of savings in output is s, that is, $\mathrm{s}=S_{t} / Y_{t}$, we can get:

$$
\mathrm{g}=\varphi \mathrm{sA}-\delta
$$

From Equation 8, it can be concluded that the economic growth rate is related to four factors: the higher the saving rate and technological progress rate are, or the lower the depreciation rate and financial intermediary cost are, the higher the economic growth rate will be. Since the depreciation rate is generally given by exogenous factors, the impact of the other three factors on economic growth is mainly considered.

From this model, we can get that the ways of the stock market to promote economic growth mainly include three aspects: the first is to increase the savings rate, namely the wealth effect, that is, when the stock value, scale and income expand, the quality and quantity of investors' assets can be improved, so as to increase savings. The second is to promote technological progress. Generally speaking, innovative companies and technology industries are faced with higher risks and longer investment cycles. The stock market can disperse risks, optimize resource allocation, improve corporate governance structure, attract investors, and bring sufficient capital to these companies to support technological progress. The third is to reduce the cost of financial intermediation through higher liquidity and less hidden cost of the stock market. The advantages of diversified product structure and risk diversification of the stock market can also reduce the idle rate of funds, which can improve the investment efficiency and promote economic growth.

\section{Empirical Analysis of the Correlation between China's Stock Market and Economic Growth}

Through the theoretical and model analysis in the previous section, we can see that the stock market can promote economic growth in many ways. This section will empirically study the correlation between the two through linear regression, Granger test and VAR model, so as to make the research more comprehensive and convincing.

\subsection{Linear Regression}

\subsubsection{Model Setting, Variable Selection and Data Description}

In this section, we will apply linear regression to analyze the driving effect of the stock market on economic growth and its significance. The model is set as follows:

$$
y_{t}=c+\alpha s_{t}+\beta z_{t}+\varepsilon_{t}
$$

Where $y_{t}$ is the dependent variable, namely GDP growth rate, $c$ is the constant term, $s_{t}$ is the core independent variable, namely the index of the stock market, $z_{t}$ is the control variable, $\alpha$ and $\beta$ are coefficients, $\varepsilon_{t}$ is the random interference term.

Referring to Levine and Zervos (1998) we measure the development of stock market from three aspects: scale, liquidity and risk dispersion. Firstly, in terms of the size of the stock market, we select the capitalization rate (recorded as Cap), which is calculated by the ratio of the total market value of the stock market in Shanghai and Shenzhen to GDP. The higher the ratio is, the larger the size of China's stock market will be. Secondly, in terms of the liquidity of stock market, we select the market transaction rate (recorded as Tac), which is calculated by the ratio of the total transaction volume of Shanghai and Shenzhen stock markets to GDP. The higher the ratio is, the better the liquidity of China's stock market will be. Thirdly, in terms of the degree of risk dispersion, we selects the volatility of the market (recorded as Vol), which is calculated by the monthly standard deviation of the volatility(the 20 day average movement) of the Shanghai Composite Index. The smaller the volatility is, the more mature the stock market will be. 
In terms of control variables, we select two variables: the first is the degree of financial deepening (recorded as Fde), which is calculated by the ratio of board money supply, to GDP. The second is the trade share (recorded as Tra), that is, the ratio of total import and export trade to GDP. Generally speaking, the higher the two indicators are, the larger the scale of finance and trade, namely the main components of GDP will be.

All the data are monthly data. Since GDP only publishes quarterly data, this paper uses Stata's linear interpolation method to supplement the monthly data of GDP. As for the time range of the variables, as $96 \%$ of the listed companies in Shanghai and Shenzhen stock markets have completed the reform of non-tradable shares by the end of 2006, therefore we set the time range from January 2007 to June 2018. The volatility of Shanghai Composite Index comes from the RESSET database, and all other data comes from the CEIC statistical database.

\subsubsection{Results}

Financial variables usually have a certain time trend, which will lead to estimation errors. In this paper, we use the augmented Dickie-Fuller test (ADF) to test the stationarity of the variables. Except for Tac, Vol and Tra, other variables are non-stationary, but the first-order differences of all variables are stationary. Therefore, all variables are treated by first order difference " $\mathrm{D}$ " in the regression model. Also, as there may be correlation between variables of the stock market, the robust estimation of variance-covariance is used in this section. The results are showed in Table 1. The value in the brackets (below the coefficient) is the $p$ value of the t-statistic, $(-4)$ represents the lag order of the variable is four.

Table-1. The results of the linear regression.

\begin{tabular}{|c|c|c|c|c|c|c|}
\hline \begin{tabular}{|l} 
Model \\
Variable
\end{tabular} & 1 & 2 & 3 & 4 & 5 & 6 \\
\hline $\mathrm{C}$ & $\begin{array}{c}-0.0008 \\
(0.137)\end{array}$ & $\begin{array}{l}-0.0009 \\
(0.101)\end{array}$ & $\begin{array}{l}-0.0009 \\
(0.124)\end{array}$ & $\begin{array}{c}-0.0009 \\
(0.126)\end{array}$ & $\begin{array}{l}-0.0009 \\
(0.125)\end{array}$ & $\begin{array}{l}-0.0009 \\
(0.127)\end{array}$ \\
\hline Fde & $\begin{array}{l}-0.0017 \\
(0.054)\end{array}$ & $\begin{array}{l}-0.0012 \\
(0.143) \\
\end{array}$ & $\begin{array}{l}-0.0013 \\
(0.138) \\
\end{array}$ & $\begin{array}{l}-0.0013 \\
(0.125) \\
\end{array}$ & $\begin{array}{l}-0.0013 \\
(0.124) \\
\end{array}$ & $\begin{array}{l}-0.0013 \\
(0.119) \\
\end{array}$ \\
\hline Tra & $\begin{array}{c}0.1019 \\
(0.288)\end{array}$ & $\begin{array}{c}0.0991 \\
(0.292) \\
\end{array}$ & $\begin{array}{c}0.1122 \\
(0.274)\end{array}$ & $\begin{array}{c}0.0980 \\
(0.308)\end{array}$ & $\begin{array}{c}0.1040 \\
(0.284)\end{array}$ & $\begin{array}{c}0.1038 \\
(0.285)\end{array}$ \\
\hline Cap & $\begin{array}{c}0.0015 \\
(0.078)\end{array}$ & & & & & \\
\hline $\begin{array}{l}\text { Cap } \\
(-4)\end{array}$ & & $\begin{array}{c}0.0021 \\
(0.033) \\
\end{array}$ & & & & \\
\hline Tac & & & $\begin{array}{l}-0.0005 \\
(0.642) \\
\end{array}$ & & & \\
\hline $\begin{array}{l}\text { Tac } \\
(-4)\end{array}$ & & & & $\begin{array}{c}0.0036 \\
(0.643) \\
\end{array}$ & & \\
\hline Vol & & & & & $\begin{array}{l}-0.2741 \\
(0.616) \\
\end{array}$ & \\
\hline $\begin{array}{l}\text { Vol } \\
(-4) \\
\end{array}$ & & & & & & $\begin{array}{l}-0.1142 \\
(0.803) \\
\end{array}$ \\
\hline$R^{2}$ & 0.0553 & 0.0847 & 0.0359 & 0.0355 & 0.0369 & 0.0350 \\
\hline F-statics & $\begin{array}{c}2.07 \\
(0.107)\end{array}$ & $\begin{array}{c}2.69 \\
(0.049)\end{array}$ & $\begin{array}{c}1.08 \\
(0.360)\end{array}$ & $\begin{array}{c}1.02 \\
(0.386)\end{array}$ & $\begin{array}{c}1.19 \\
(0.317)\end{array}$ & $\begin{array}{c}1.07 \\
(0.365)\end{array}$ \\
\hline
\end{tabular}

From Table 1 we can get that the size of the stock market has a positive and the volatility has a negative role in promoting the current economic growth, and their lag value has the same effect on the economic growth, which is consistent with the theory. The current liquidity of stock market has a negative impact on economic growth, and the lag value has a positive impact on economic growth, which indicates that the liquidity of stock market has a lag effect on economic growth. From the perspective of significance, the impact of stock market size on economic growth is more significant, while the significance of other indicators is relatively weak, indicating that China's stock market has reached a certain scale and has a significant driving effect on economic growth. However, due to the imperfect development of the stock market, such as imperfect structure, institution of the stock market, and human intervention, etc, the correlation between stock market liquidity, volatility and economic growth is weak.

\subsection{Granger Causality Analysis}

Granger causality test is used to test the causal relationship between variables. The Granger causality between two economic variables $\mathrm{X}$ and $\mathrm{Y}$ is defined as: if the past information of variables $\mathrm{X}$ and $\mathrm{Y}$ is included, 
the prediction effect of variable $\mathrm{Y}$ is better than that of $\mathrm{Y}$ only by the past information of $\mathrm{Y}$, that is, variable $\mathrm{X}$ helps to explain the future change of variable $\mathrm{Y}$, then variable $\mathrm{X}$ is considered to be the Granger cause of variable $\mathrm{Y}$. This test is an important way to analyze the causal relationship and mechanism between stock market and economic growth.

\begin{tabular}{l|l|c|c}
\multicolumn{3}{c}{ Table-2. Granger causality test. } & P-value \\
\hline Variable & Assumption & $\chi^{2}$-value & 0.0584 \\
GDP & GDP is not the Granger cause of Cap & 3.0366 & 0.081 \\
Cap & Cap is not the Granger cause of GDP & 0.8278 & 0.363 \\
GDP & GDP is not the Granger cause of Tac & 2.3524 & 0.125 \\
\hline Tac & Tac is not the Granger cause of GDP & 0.3607 & 0.548 \\
GDP & GDP is not the Granger cause of Vol & 0.0099 & 0.921 \\
\hline
\end{tabular}

Table 2 shows that the Granger test rejects the assumption that Cap is not the Granger cause of GDP at the $10 \%$ confidence level, but does not reject other assumptions. Therefore, it can be concluded that the stock market scale is the Granger cause of economic growth at the $10 \%$ confidence level, that is, the stock market scale leads to economic growth to a certain extent. This is consistent with the results of the previous part, indicating that China's stock market also has a significant role in promoting economic growth.

\subsection{VAR Model}

\subsubsection{Model Setting}

In this section we will apply vector autoregression model(VAR). VAR model does not focus on the explanation of estimated parameters, but studies the dynamic relationship among multiple variables through impulse response and variance decomposition. The general form of VAR model is as follows,

$$
y_{t}=A_{1} y_{t-1}+\cdots+A_{p} y_{t-p}+B_{1} x_{t}+\cdots+B_{r} x_{t-r}+\varepsilon_{t}
$$

Where, $y_{t}, x_{t}$ is the vector of endogenous and exogenous variables respectively, $p$ and $r$ are the order of $\mathrm{lag}, \varepsilon_{t}$ is a random perturbation term. The equation shows that in VAR system, endogenous variable is determined by its own lag term and exogenous variables and their lag terms at the same time. We take economic growth as the dependent variable and stock market as the independent variables to set a VAR model. As VAR model must satisfy some assumptions, it should be tested before further analysis. Firstly, according to AIC and SIC criteria, the lag order of the VAR model is determined to be 1. Secondly, it is necessary to test the stability of VAR model. The main method is unit root test, that is, the reciprocal of all unit root modules of VAR model is less than 1. As shown in Figure 1, the unit roots of VAR model are all in the unit circle, which means that the model is stable.

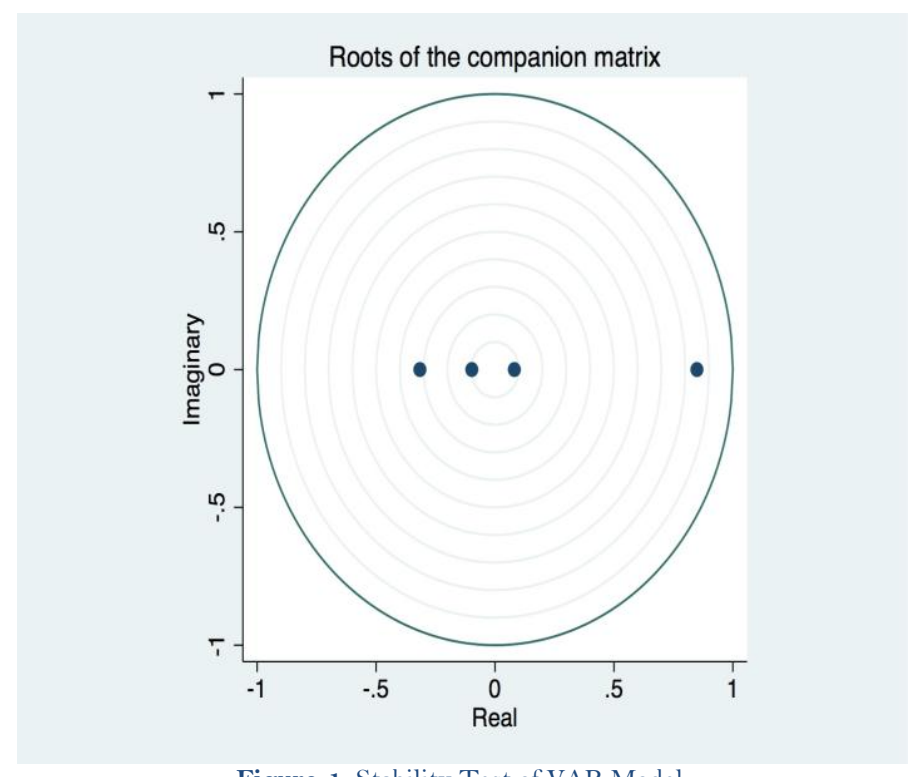

Figure-1. Stability Test of VAR Model.

4.3.2. Impulse Response Analysis

Impulse response describes the impact on the current and future values of all endogenous variables after a standard deviation impact is imposed on the random error. Figure 2.a-2.c shows the results. The horizontal 
axis represents the impact time (month), the vertical axis represents the response of each variable to a standard deviation innovation impact, and the shaded part is the $95 \%$ confidence interval.

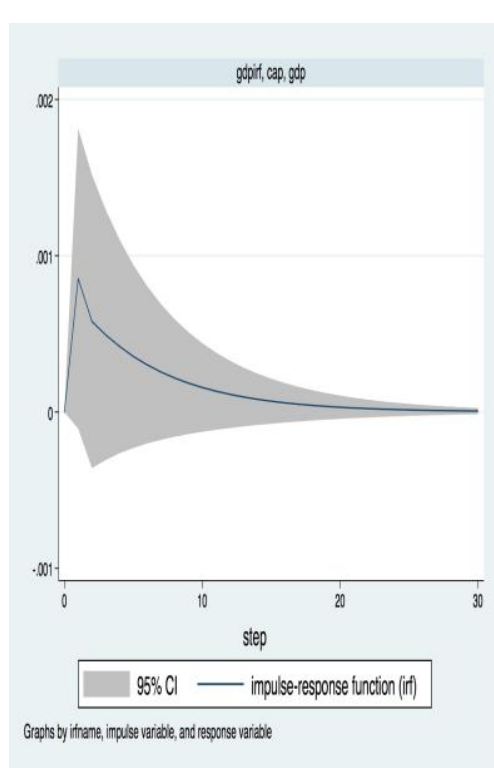

a. GDP responses to Cap

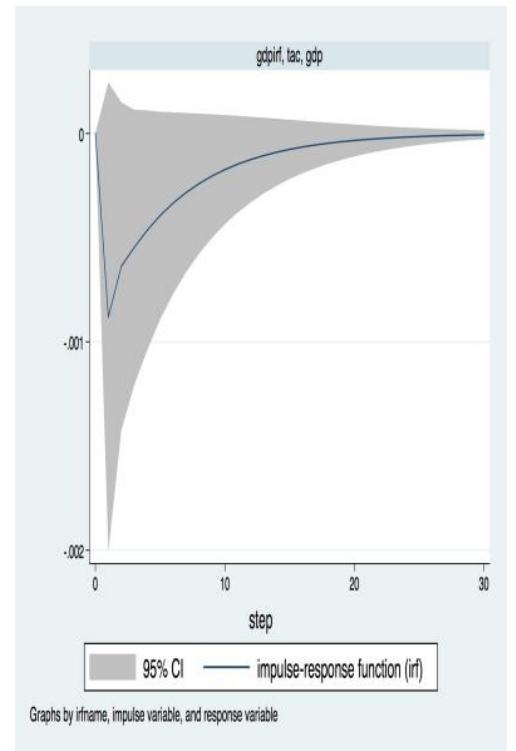

b. GDP responses to Tac

Figure-2. Impulse response of the VAR model.

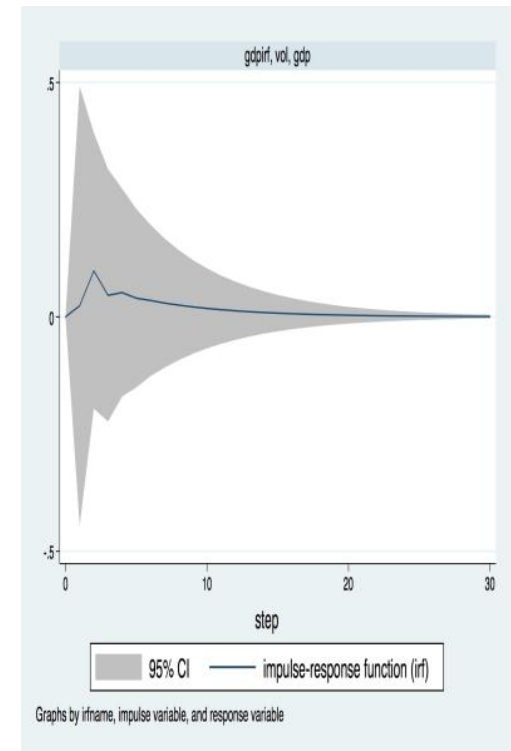

c. GDP responses to Vol

According to Figure 2, we could analyze the impact of stock market on economic growth from two aspect term. Firstly, the response of economic growth to stock market. The scale of the stock market has a big and positive impact on economic growth, the liquidity of stock market has a similar reverse impact on economic growth, while the volatility of stock market has a small positive impact on economic growth. Secondly, the duration of the impact. The impact of the size and liquidity of the stock market volatility on economic growth last for a long time, which tends to be stable in 12 periods, that is, one year later, while the impact of volatility is relatively short, about six periods, that is, half a year.

According to these results, the impact of the liquidity and volatility of the stock market is somewhat inconsistent with the expectation, which means that the scale of China's stock market plays a successful role in driving economic growth, and the stock market is becoming an important channel for financing. However, due to the immature development of the market, the impact of the liquidity and volatility of stock market on economic growth is not clear, which is consistent with the previous conclusion.

\subsubsection{Analysis of Variance Decomposition}

The variance decomposition of VAR model mainly reveals the proportion of changes caused by the impact of the series itself and other variables. Table 3 is the result of variance decomposition of GDP, namely the changes of GDP caused by itself, Cap, Tac and Vol respectively.

We can see that the change of GDP is most affected by itself, which is in line with the general expectation. However, the explanation effect of stock market on GDP change is very small, which indicates that the impact of the shock from the stock market on China's economic growth is also very small.

Table-3. Variance Decomposition of GDP

\begin{tabular}{c|c|c|c|c}
\hline Lag Order & GDP & Cap & Tac & Vol \\
\hline 1 & 0.99 & 0.01 & 0.01 & 0.00 \\
\hline 2 & 0.98 & 0.01 & 0.0 & 0.00 \\
\hline 3 & 0.98 & 0.01 & 0.01 & 0.00 \\
\hline 4 & 0.98 & 0.01 & 0.01 & 0.00 \\
\hline 5 & 0.98 & 0.01 & 0.01 & 0.00 \\
\hline 6 & 0.98 & 0.01 & 0.01 & 0.00 \\
\hline 7 & 0.98 & 0.01 & 0.01 & 0.00 \\
\hline 8 & 0.98 & 0.01 & 0.01 & 0.00 \\
\hline
\end{tabular}

\section{Conclusions}

From the empirical results, as an important financial tool, the stock market has made great contribution to the development of China's real economy. But on the whole, the correlation between China's stock market and economic growth is weak, especially the mechanism of liquidity and volatility of stock market on economic growth needs to be optimized. The possible reasons are that China's stock market and financial market are 
subject to many human interventions, and the structure of the market, the operation mechanism and system are still imperfect. So we need to optimize the market to better serve the real economy.

\section{References}

Arestis, P., Demetriades, P. O., \& Luintel, K. B. (2001). Financial development and economic growth: The role of stock markets. Journal of Money, Credit and Banking, 33(1), 16-41.Available at: https://doi.org/10.2307/2673870.

Brown, J. R., Martinsson, G., \& Petersen, B. C. (2017). Stock markets, credit markets, and technology-led growth. Journal of Financial Intermediation, 32, 45-59.Available at: https://doi.org/10.1016/j.jfi.2016.07.002.

Chen, J., Wang, Y. J., \& Chen, J. X. (2004). The influence of stock market on technology progress and economic growth. Journal of Xian Jiaotong University Social Sciences, 3, 67-70.

Cho, Y. J. (1986). Inefficiencies from financial liberalization in the absence of well-functioning equity markets. Journal of Money, Credit and Banking, 18(2), 191-199.Available at: https://doi.org/10.2307/1992202.

Duan, H. B., \& Yang, G. (2009). Stock market development and economic growth: Evidence of China. Journal of Central University of Finance and Economics, 12, 31-36.

Levine, R., \& Zervos, S. (1998). Capital control liberalization and stock market development. World Development, 26(7), 1169-1 183.Available at: https://doi.org/10.1016/s0305-750x(98)00046-1.

Liu, Y. S. (2011). The stock market development and the economic growth: From the view of liquidity. Economic Research Guide, 17, 89-92.

Mao, Y., \& Wu, R. (2007). Does the stock market act as a signal for real activity? Evidence from Australia. Economic Papers: A Journal of Applied Economics and Policy, 26(2), 180-192.Available at: https://doi.org/10.1111/j.175934.1.2007.tb01015.x.

Song, Y. C., \& Li, N. B. (2014). Research on the matching between stock market and economic growth. Seeker, 4, 99-104.

Tan, R. Y. (1999). An empirical study on the relationship between financial development and economic growth in China. Economic Research Journal, 10, 53-61.

Wang, Z. Y., \& Ma, L. (2005). Research on the relationship between the stock market and the economy growth. Finance and Trade Research, 1, 94-96.

Yang, Z. B., \& Kuang, X. (2004). An empirical study of the relationship between stock market and economic growth in China. Finance and Trade Research, 3, 61-67. 